University of Nebraska - Lincoln

DigitalCommons@University of Nebraska - Lincoln

Faculty Publications from the Harold W. Manter Laboratory of Parasitology

2010

Structural Restoration of Nematodes and Acanthocephalans

Fixed in High Percentage Alcohol Using Dess Solution and

Rehydration

\author{
Soraya Naem \\ Urmia University \\ Christopher Pagan \\ University of California - Davis \\ Steven A. Nadler \\ University of California - Davis, sanadler@ucdavis.edu
}

Follow this and additional works at: https://digitalcommons.unl.edu/parasitologyfacpubs

Part of the Parasitology Commons

Naem, Soraya; Pagan, Christopher; and Nadler, Steven A., "Structural Restoration of Nematodes and Acanthocephalans Fixed in High Percentage Alcohol Using Dess Solution and Rehydration" (2010). Faculty Publications from the Harold W. Manter Laboratory of Parasitology. 717.

https://digitalcommons.unl.edu/parasitologyfacpubs/717

This Article is brought to you for free and open access by the Parasitology, Harold W. Manter Laboratory of at DigitalCommons@University of Nebraska - Lincoln. It has been accepted for inclusion in Faculty Publications from the Harold W. Manter Laboratory of Parasitology by an authorized administrator of DigitalCommons@University of Nebraska - Lincoln. 


\title{
Structural Restoration of Nematodes and Acanthocephalans Fixed in High Percentage Alcohol Using Dess Solution and Rehydration
}

\author{
Soraya Naem, Christopher Pagan ${ }^{\star}$, and Steven A. Nadler ${ }^{\star \dagger}$, Department of Pathobiology, Faculty of Veterinary Medicine, Urmia University, \\ Urmia, Iran; *Department of Nematology, University of California, Davis, California 95616; †To whom correspondence should be addressed. \\ e-mail: sanadler@ucdavis.edu
}

\begin{abstract}
Ninety-five percent ethanol is the most widely used field and laboratory preservative for nematodes and other helminth specimens intended for use in molecular systematics. Preservation of nematodes in high-concentration alcohols results in structural dehydration artifacts, including shrinkage and body surface distortions sufficient to obscure features required for morphological identification and analysis, thereby compromising precise morphometrics. However, treating dehydrated nematodes using a solution of DMSO, disodium EDTA, and $\mathrm{NaCl}$, followed by rehydration in water produces marked improvements in specimen shape and surface features, resulting from diffusion of water into the tissues and pseudocoelom as the internal salt concentration is reduced. Following rehydration, tissue samples can be obtained for molecular research and individuals can be fixed for morphological examination. This treatment method is demonstrated for species of 3 nematode genera that vary substantially in body size (Baylisascaris, Uncinaria, and Bidigiticauda). The method also works on nematodes that have been cut in half, provided the individuals are large enough to be folded and clamped during treatment. This method appears promising for other helminths, although for an acanthocephalan, the treatment restored the body surface but failed to reverse the retracted proboscis.
\end{abstract}

Molecular methods have become an integral part of parasite systematics and are used with increasing frequency for investigations of phylogeny, species delimitation, and population genetic structure (Nadler, 1990, 1995, 2002; Tibayrenc, 1995; McManus and Bowles, 1996; Adams, 1998; Anderson et al., 1998). It is generally understood that systematic studies benefit from integration of morphological and molecular approaches (Kluge, 1998; Wheeler, 2008) and, for certain types of investigations, this combination is essential. For example, when morphological diagnosis of a species is difficult, or species-level diversity is poorly known, e.g., cryptic species complexes, it is particularly important to obtain molecular and morphological data from the same individual specimens to gain an accurate understanding of species-level systematics (Pérez-Ponce de León and Nadler, 2010). This can be difficult to achieve because commonly used methods for preservation of DNA are often sub-optimal for preserving morphological features of parasites, and vice-versa. In particular, concentrations of alcohols commonly used for preservation of specimens for DNA analysis frequently induce structural artifacts in multi-cellular parasites that make them practically useless for detailed and comprehensive morphological study. Preparing different sub-samples of specimens, as well as using different preservation procedures, one optimized for morphology and another for DNA, may work in some cases, but is less than ideal. This is particularly true if there are few specimens from a host, or if the sample may contain several morphologically similar congeneric species. Development and use of methods that can provide improved preservation of both molecular and morphological features of specimens is important for advancement in parasite systematics. Similarly, methods that can improve the morphological features of specimens originally preserved for molecular study can provide added value for these collections; the present report details one such procedure.

Yoder et al. (2006) discussed several characteristics of an ideal, multipurpose fixative for nematodes including suitable preservation of DNA and morphology, minimal hazards with respect to toxicity and flammability, ease of transportation to field sites, fewer restrictions on commercial shipping, and ease of continued storage following preservation. DESS, a solution of dimethyl sulfoxide (DMSO), disodium EDTA, and $\mathrm{NaCl}$, has been successfully tested for short-term $(\sim 6 \mathrm{mo})$ room-

DOI: $10.1645 / G E-2402.1$ temperature preservation of nematode DNA and morphology (Yoder et al., 2006) and longer-term ( 2 yr) preservation of DNA from mammalian tissues (Kilpatrick, 2002). DESS provides excellent preservation of the morphological features of nematodes, including surface structures, as revealed by scanning electron microscopy (Yoder et al., 2006). In their study of free-living nematodes and some parasites of invertebrates, Yoder et al. (2006) reported successful PCR amplification of nuclear ribosomal gene regions of up to $1,800 \mathrm{bp}$ in $\sim 80 \%$ of the specimens tested (Yoder et al., 2006). DESS has also been tested for preservation of monogeneans and fish gill tissues, and the results confirmed excellent, short-term preservation (up to 8 wk tested experimentally, with longer preservation periods suggested) of parasites and gills, with PCR amplification and DNA sequencing results comparable to $99 \%$ ethanol (Strona et al., 2009). In other studies, PCR-based evaluations of 5 solutions used for field preservation of DNA for marine invertebrate tissues ( $\mathrm{NaCl}-\mathrm{CTAB}, 70 \%$ ethanol, DESS, Queen's lysis buffer, and urea buffer) also indicated that DESS was best for preserving both the physical structure of tissues and the DNA, as assessed by amplification (Dawson et al., 1998), a result previously reported for vertebrate tissues (Seutin et al., 1991). However, the type of tissue and the environmental conditions are also important factors influencing DNA degradation (Post et al., 1993) and, although DESS would appear to be a promising solution for nematodes and monogeneans, this morphological and molecular preservation needs to be verified for other parasite taxa.

DMSO in DESS crosses tissue membranes and changes the structure of membrane-bound proteins (Jacob, 1971; Seutin et al., 1991), enhancing the transport of certain materials into cells and tissue spaces, particularly molecules of lower molecular weight. Investigators using DESS should, therefore, avoid direct contact with solutions containing preserved parasites because the membrane transport properties of DMSO may increase exposure to small immunogenic molecules such as parasite haptens. For DESS, increased membrane permeability results in $\mathrm{NaCl}$ and EDTA transport into cells (and the pseudocoelom of nematodes); these compounds inhibit nucleases that can degrade DNA through precipitation of proteins (salt) and chelation of required enzymatic cofactors (EDTA). High amounts of $\mathrm{NaCl}$ and EDTA can also be inhibitory for PCR amplification, and the reported success rate for PCR amplification of nematode ribosomal DNA from DESS-preserved specimens (Yoder et al., 2006) is somewhat lower than for ethanol-preserved specimens, in our experience. Unpublished work indicates that some nematode specimens with good morphological preservation by DESS may inexplicably fail to yield PCR amplicons (P. DeLey, pers. comm.), perhaps resulting from salt or chelator inhibition that could be mitigated by pre-incubating DESSpreserved specimens in lysis buffer or in $10 \mathrm{mM}$ Tris- $\mathrm{HCl}$ buffers containing $0.5-1 \mathrm{mM}$ EDTA prior to extraction. Crystalline (salt) precipitates present in some DESS-preserved specimens may also interfere with certain observations, necessitating additional preparation prior to morphological study. Despite certain advantages of DESS, e.g., reduced flammability and much lower toxicity than formalin, it is not yet commonly used in most laboratories, and DMSO and EDTA are muchless widely available for purchase in field situations when compared to alcohol.

Undenatured ethanol and, to a lesser extent 2-propanol, are the mostwidely used field and laboratory preservatives for specimens intended for DNA extraction (Nietfeldt and Ballinger, 1989). Ultracold freezing is, without question, the most effective method for preservation of all macromolecular resources, including DNA, RNA, and proteins (Dessauer et al., 1996), and many single-copy nuclear genes are more readily obtained using RT-PCR, which requires preservation of mRNA that is optimally preserved for the long-term through ultracold cryopreservation 

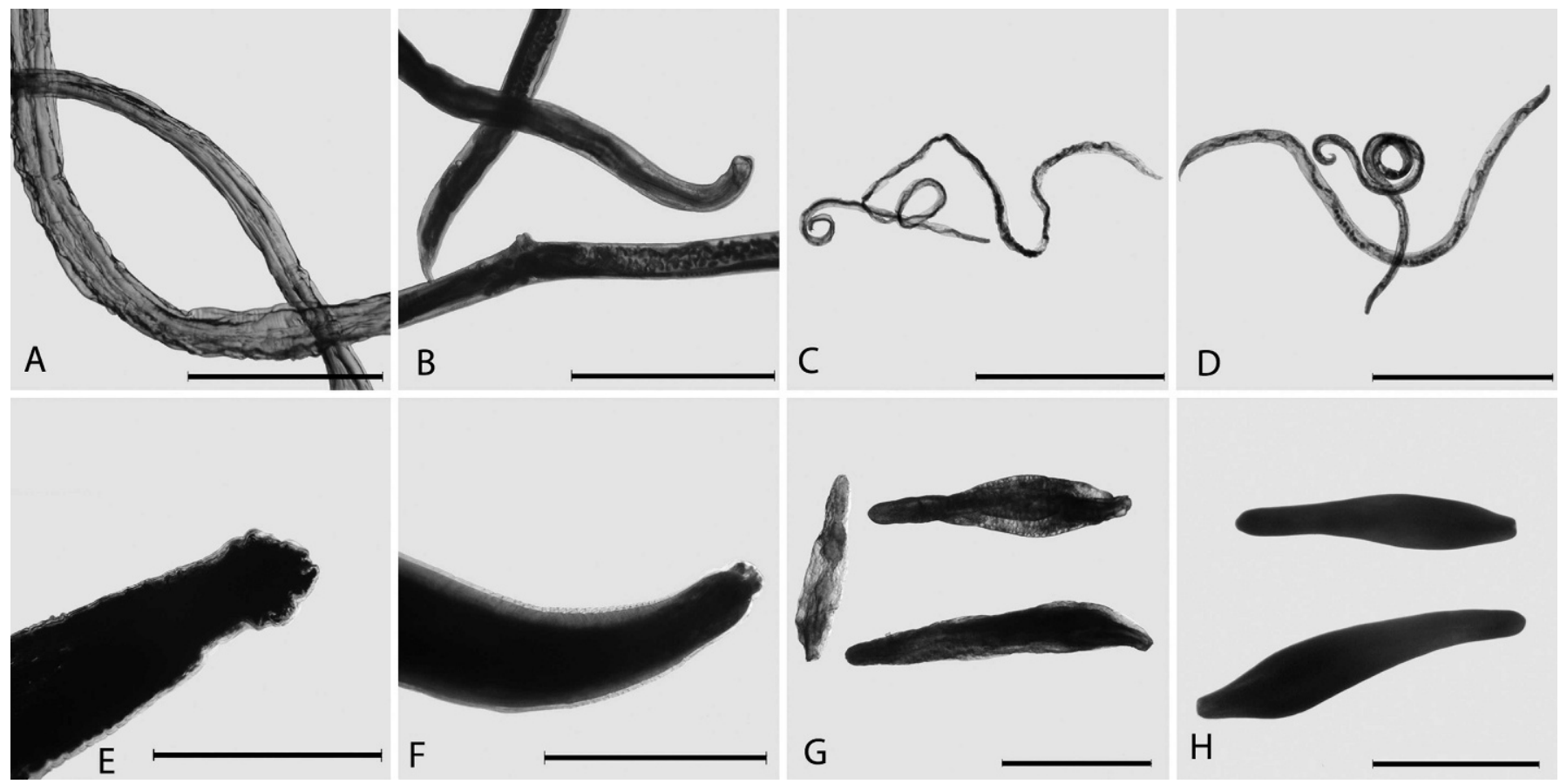

Figure 1. Stereomicroscopic images of nematodes $(\mathbf{A}-\mathbf{F})$ and acanthocephalans $(\mathbf{G}, \mathbf{H})$ taken before (panels A, C, E, G), and after (panels B, D, F, H), DESS treatment and rehydration. Uncinaria sp. (panels A, B), Bidigiticauda sp. (panels C, D), Baylisascaris procyonis (panels E, F), and Echinorhynchus salmonis (panels G, H). Panels A, C, E, and G show specimens from ethanol with typical shrinkage artifacts. Panels B, D, F, and H show the same individual specimens (1 specimen in panel $\mathrm{G}$ is missing in panel $\mathrm{H}$ ) following DESS treatment and rehydration. Bar $=2 \mathrm{~mm}$.

rather than use of commercially available RNA stabilization reagents However, frozen specimens of macroparasites are rarely useful for detailed morphological study, and liquid nitrogen presents additional complications for fieldwork and the subsequent airline transportation of specimens. Preservation of specimens in alcohol results in dehydration of the sample, which protects DNA by denaturation of endogenous proteins that degrade DNA, including hydrolytic and oxidative nucleases (Dessauer et al., 1996; Flournoy et al., 1996), but results in dehydration of the sample. Solutions of higher alcohol concentration have a greater dehydration effect and, therefore, are expected to provide better, long-term DNA protection. For example, mammalian tissues stored in $95 \%$ ethanol at room temperature for 2 yr yielded high molecular weight DNA and were successfully used for PCR amplification (Kilpatrick, 2002). In contrast, studies using 70\% ethanol have reported more-variable results regarding DNA preservation (Seutin et al., 1991; Holzmann and Pawlowski, 1996; Dawson et al., 1998), perhaps reflecting differences in dehydration efficacy, but also in tissue type and storage conditions. Unfortunately, preservation of nematodes and other helminths in high-concentration alcohols (95-100\% ethanol is typical) usually results in structural dehydration artifacts, including shrinkage of specimens and body surface distortions sufficient to obscure features required for morphological identification and analysis, and the compromising of precise morphometrics (Fig. 1). Relaxing the specimens, e.g., heat-killing the nematodes, prior to alcohol preservation does not prevent these shrinkage artifacts because subsequent rapid alcohol dehydration removes too much water from cells and from the pseudocoelomic cavity. Methods have been described to straighten parasite specimens fixed in situ or in bulk, without relaxation (Pritchard and Kruse, 1982), but this does not alter dehydration-induced surface changes. In contrast, fixation of specimens in DESS solution is reported to cause only short-term shrinkage artifacts that do not interfere with subsequent morphological observations (Yoder et al., 2006).

The procedure we used takes advantage of the membrane permeability of DMSO in combination with its transport properties for salts in the DESS solution (disodium EDTA and $\mathrm{NaCl}$ ). These properties remain intact in ethanol-preserved tissues of nematodes, as our results revealed. Our experiments were conducted on nematodes preserved in $95-100 \%$ ethanol for periods of up to $12 \mathrm{yr}$; some of these taxa were also stored at
-20 C. Nematodes tested represented sizes ranging from $\sim 6-370 \mathrm{~mm}$, including Uncinaria sp. (Ancylostomatidae), Baylisascaris procyonis Stefanski and Zarnowski 1951 (Ascarididae), and Bidigiticauda sp. (Trichostrongylidae). A solution of DMSO/EDTA/NaCl or DESS (Seutin et al., 1991) was used that consisted of $20 \%$ (v/v) dimethyl sulfoxide and $0.25 \mathrm{M}$ disodium EDTA ( $\mathrm{pH}$ 8.0) saturated with $\mathrm{NaCl}$. Individual specimens were photographed before and after treatment (Fig. 1). For nematodes, individual specimens were usually transferred from $95-100 \%$ ethanol to $70 \%$ ethanol for equilibration and then immersed in DESS solution in 1 of 3 experimental exposure treatments (24-, 48-, or 72-hr immersion). Experiments included 3 individuals of both sexes, for each nematode tested, and control specimens (stored in $70 \%$ ethanol before water immersion). Following DESS immersion, specimens were transferred to pure water and periodically monitored for reduction in body surface artifacts resulting from osmosis-induced swelling. The change in specimen volume resulted from diffusion of water into the tissues (and particularly the body cavity) as the high internal salt concentration was reduced. Marked improvements in specimen body shape and surface features were observed between $5 \mathrm{~min}$ and $1 \mathrm{hr}$ of water treatment, with a faster rate of change in smaller specimens, perhaps due to differences in surface-to-volume ratio. Following rehydration, specimens were fixed in AFA prior to morphological examination. Alternatively, tissues can be sampled for molecular research prior to AFA fixation. This restoration of structure was stable following AFA fixation. There was no difference in effectiveness between the 3 different DESS time courses and, at least for these nematode species, 24-hr immersion in DESS was sufficient. Clearly, this result might vary with other species, tissue types, exterior permeability, and specimen sizes. Osmotic changes resulting from increased turgor pressure of the pseudocoelom require an intact cuticle. However, large nematodes (B. procyonis) that had been cut in half (for prior sampling of tissues for DNA) could also be restored using DESS, provided that the body was folded over and clamped prior to immersion of the nematode in DESS.

We also evaluated this method for an acanthocephalan species (Echinorhynchus salmonis Müller, 1784) to test its ability to reverse an ethanol-fixed "retracted" proboscis. This is a frequent occurrence for (non-relaxed) specimens in which observation and counting of the 
systematically important proboscis hooks is obscured. For this acanthocephalan, this treatment restored the body surface (Figs. 1g, h) but did not reverse the retraction of the proboscis, presumably because the retractor muscles were preserved in the contracted state. Although the proboscis did not evert with treatment, the procedure did soften the body (in comparison to the condition in ethanol), making it easier to dissect out the retracted proboscis for examination.

We thank Corwin Parker for preparing the figure plates. This research was conducted during the sabbatical leave of S. Naem to the Department of Nematology, University of California, Davis, California. This investigation was supported in part through an award from the National Science Foundation (NSF) program, Partnerships for Enhancing Expertise in Taxonomy (DEB-0731516).

\section{LITERATURE CITED}

Adams, B. J. 1998. Species concepts and the evolutionary paradigm in modern nematology. Journal of Nematology 30: 1-21.

Anderson, T. J. C., M. S. Blouin, and R. N. Beech. 1998. Population biology of parasitic nematodes: Applications of genetic markers. Advances in Parasitology 41: 221-283.

Dawson, M. N., K. A. Raskoff, and D. K. Jacobs. 1998. Field preservation of marine invertebrate tissue for DNA analyses. Molecular Marine Biology and Biotechnology 7: 145-152.

Dessauer, H. C., C. J. Cole, and M. S. Hafner. 1996. Collection and storage of tissues. In Molecular systematics, D. M. Hillis, C. Moritz, and B. K. Mable (eds.). Sinauer Associates, Inc., Sunderland, Massachusetts, p. 29-47.

Flournoy, L. E., R. P. Adams, and R. N. Pandy. 1996. Interim and archival preservation of plant specimens in alcohols for DNA studies. Biotechniques 20: 657-660.

Holzmann, M., AND J. Pawlowski. 1996. Preservation of formanifera for DNA extraction and PCR amplification. Journal of Foraminiferal Research 26: 264-267.

JАСов, S. W. 1971. Pharmacology of DMSO. In Dimethyl sulfoxide, S. W. Jacob, E. E. Rosenbaum, and D. C. Wood (eds.). Marcel Dekker, Inc., New York, New York, p. 99-112.

KilPATRICK, C. W. 2002. Noncryogenic preservation of mammalian tissues for DNA extraction: An assessment of storage methods. Biochemical Genetics 40: 53-62.
KLugE, A. G. 1998. Total evidence or taxonomic congruence: Cladistics or consensus classification. Cladistics 14: 151-158.

McManus, D. P., And J. Bowles. 1996. Molecular genetic approaches to parasite identification: Their value in diagnostic parasitology and systematics. International Journal for Parasitology 26: 687704.

NADLER, S. A. 1990. Molecular approaches to studying helminth population genetics and phylogeny. International Journal for Parasitology 20: 11-29.

. 1995. Microevolution and the genetic structure of parasite populations. Journal of Parasitology 81: 395-403.

. 2002. Species delimitation and nematode biodiversity: Phylogenies rule. Nematology 4: 615-625.

Nietfeldt, J. W., AND R. E. Ballinger. 1989. A new method for storing animal tissues prior to mtDNA extraction. Biotechniques 7: 3132.

Pérez-Ponce De león, G., and S. A. Nadler. 2010. What we don't recognize can hurt us: A plea for awareness about cryptic species. Journal of Parasitology 96: 453-464.

Post, R. J., P. K. Flook, and A. L. Millest. 1993. Methods for the preservation of insects for DNA studies. Biochemical Systematics and Ecology 21: 85-92.

Pritchard, M. H., and G. O. W. Kruse. 1982. The collection and preservation of animal parasites. University of Nebraska Press, Lincoln, Nebraska, 141 p.

Seutin, G., B. N. White, and P. T. Boag. 1991. Preservation of avian blood tissue samples for DNA analyses. Canadian Journal of Zoology-Revue Canadienne De Zoologie 69: 82-90.

Strona, G., F. Stefani, and P. Galli. 2009. Field preservation of monogenean parasites for molecular and morphological analyses. Parasitology International 58: 51-54.

Tibayrenc, M. 1995. Population genetics of parasitic protozoa and other microorganisms. Advances in Parasitology 36: 47-115.

Wheeler, Q. D. 2008. The new taxonomy. CRC Press, Boca Raton, Florida, $237 \mathrm{p}$.

Yoder, M., I. Tandingan De Ley, W. I. King, M. Mundo-Ocampo, J. Mann, M. Blaxter, L. Poiras, and P. De Ley. 2006. DeSS: A versatile solution for preserving morphology and extractable DNA of nematodes. Nematology 8: 367-376. 